\title{
Adenosine signaling and function in glial cells
}

\author{
D Boison ${ }^{*, 1}$, J-F Chen² and BB Fredholm ${ }^{3}$
}

Despite major advances in a variety of neuroscientific research fields, the majority of neurodegenerative and neurological diseases are poorly controlled by currently available drugs, which are largely based on a neurocentric drug design. Research from the past 5 years has established a central role of glia to determine how neurons function and, consequently, glial dysfunction is implicated in almost every neurodegenerative and neurological disease. Glial cells are key regulators of the brain's endogenous neuroprotectant and anticonvulsant adenosine. This review will summarize how glial cells contribute to adenosine homeostasis and how glial adenosine receptors affect glial function. We will then move on to discuss how glial cells interact with neurons and the vasculature, and outline new methods to study glial function. We will discuss how glial control of adenosine function affects neuronal cell death, and its implications for epilepsy, traumatic brain injury, ischemia, and Parkinson's disease. Eventually, glial adenosine-modulating drug targets might be an attractive alternative for the treatment of neurodegenerative diseases. There are, however, several major open questions that remain to be tackled.

Cell Death and Differentiation (2010) 17, 1071-1082; doi:10.1038/cdd.2009.131; published online 18 September 2009

It is becoming increasingly clear that inflammatory processes play an important role in neurodegenerative disease, just as inflammation is becoming increasingly implicated in various systemic diseases elsewhere in the body. ${ }^{1}$ As the immune responses in brain show uncommon features, it was long considered to be 'immune privileged'. However, cells that are involved in adaptive immune reactions do enter the brain, and this can result in major CNS pathology. Multiple sclerosis is an important example. Furthermore, immune reactions, often attributable to the innate immune system, feature in many, if not all, neurodegenerative diseases. Microglial cells, astrocytes, endothelial cells, oligodendrocytes, and neurons all produce signals to orchestrate these reactions. Arachidonic acid metabolites, nitric oxide, cytokines, and chemokines all appear to play some role. Recently, the role of ATP and adenosine as critically important signaling molecules has become appreciated. ${ }^{2,3}$ This awareness that a multiplicity of signals other than those principally involved in nerve-nerve communication play a role in neurodegenerative disease has also meant that we have to consider other cells than neurons as critically important players. The present brief review will focus on adenosine (and to a lesser extent ATP) signaling, and the role of glial cells in neurodegenerative disease. The review will feature results from the authors' own work more prominently than would be motivated from an objective standpoint.

\section{Glial Control of Adenosine Homeostasis}

In mammals, purine de novo synthesis proceeds via formation of IMP, which is then converted into AMP; however, there is no de novo synthesis pathway for adenosine. Physiologically, intracellular adenosine can be formed by either dephosphorylation of AMP by $5^{\prime}$-nucleotidase, or, alternatively, by hydrolysis of $S$-adenosylhomocysteine, whereas extracellular adenosine can be formed from released adenine nucleotides by a cascade of ectonucleotidases. ${ }^{4}$ Two metabolic pathways are responsible for the removal of adenosine: deamination into inosine via adenosine deaminase (ADA; EC 3.5.4.4) and phosphorylation into AMP via adenosine kinase (ADK; EC 2.7.1.20). Based on its low $K_{\mathrm{M}}$ for adenosine, ADK is considered to be the primary route of adenosine metabolism. ${ }^{5}$ Recent findings indicate that extracellular levels of adenosine, and consequently the levels close to synapses, are largely regulated by astrocytes, ${ }^{6-10}$ and an astrocyte-based adenosine cycle has been proposed. ${ }^{11,12}$

Glial release of ATP as source for extracellular adenosine. ATP can be released from neurons and astrocytes, is identified as a neurotransmitter in both CNS and PNS, and exerts a multitude of largely excitatory effects by activation of specific ATP receptors (P2X and P2Y receptors). ${ }^{13}$ Vesicular release has also been clearly

\footnotetext{
${ }^{1}$ Robert Stone Dow Neurobiology Laboratories, Legacy Research, Portland, OR 97232, USA; ${ }^{2}$ Department of Neurology, Boston University School of Medicine, Boston, MA 02118, USA and ${ }^{3}$ Department of Physiology and Pharmacology, Karolinska Institutet, Stockholm, S-17177, Sweden

${ }^{*}$ Corresponding author: D Boison, Robert Stone Dow Neurobiology Laboratories, Legacy Research, 1225 NE 2nd Avenue, Portland, OR 97232, USA.

Tel.: + 1503413 1754; Fax: + 1503413 5465; E-mail: dboison@ downeurobiology.org

Keywords: astrocyte; adenosine receptor; adenosine kinase; epilepsy; excitotoxicity; neurodegeneration

Abbreviations: AAT, adenosine augmentation therapy; ADA, adenosine deaminase; ADK, adenosine kinase; AMPA, $\alpha$-amino-3-hydroxyl-5-methyl-4-isoxazolepropionate; AR, adenosine receptor; CBF, cerebral blood flow; CCI, controlled cortical impact; EGFP, enhanced green fluorescent protein; FACS, fluorescence activated cell sorting; MAP, microtubule associated protein; NMDA, N-methyl-D-aspartic acid; MPTP, 1-methyl-4-phenyl-1,2,3,6-tetrahydropyridine; NOS, nitric oxide synthase; NTPDase, nucleoside triphosphate diphosphohydrolase; PD, Parkinson's disease; SNARE, soluble NSF attachment protein; SOD, superoxide dismutase Received 10.6.09; revised 21.7.09; accepted 27.7.09; Edited by RA Knight; published online 18.9.09
} 
demonstrated from endocrine cells, and here release of ATP may differ in several ways from that of the hormone, because of so-called kiss-and-run release. ${ }^{14}$ Thus, ATP can be released even in situations when the vesicle fusion is too incomplete and transient to allow release of the stored hormone. Perhaps this can occur also in nerves. However, under physiological conditions the vesicular release of ATP, not from neurons, but from astrocytes, has been identified as a major source of synaptic adenosine. ${ }^{15}$ Transgenic mice that express a dominant-negative soluble NSF attachment protein (SNARE) domain selectively in astrocytes were characterized by the loss of the adenosine $A_{1}$ receptormediated tonic inhibition in synaptic slices, indicating that under physiological conditions astrocytic release of ATP (followed by degradation into adenosine via ectonucleotidases) is a major source of adenosine ${ }^{15}$ that affects synaptic transmission. A kiss-and-run-like exocytotic release of ATP has been detected in astrocytes. ${ }^{16}$ Another, possibly related, mechanism involves release of ATP from a lysosome pool in astrocytes. ${ }^{17}$ However, astrocytes appear to use also other mechanisms to release ATP as a signal. One of those involve connexin hemichannels, ${ }^{18}$ but recent work provides strong reason to assume that pannexin-1, rather than connexin-43, provides the most responsible channel. ${ }^{19}$ Another proposal is that ATP is released via maxi-anion channels, and this may be particularly important in astrocytic swelling. ${ }^{20}$ The $\mathrm{P}_{2} \mathrm{X}_{7}$ receptor may in some conformations allow ATP to be released. Finally, ATP may be released whenever there are increases in membrane volume via incorporation of intracellular vesicles into the membrane, or when there is a shedding of small vesicles. ${ }^{21}$ In addition to the mechanisms described above, astrocytes can directly release adenosine, especially in response to hypoxic stimulation, ${ }^{6,22}$ even though release of adenosine per se is more typical of neurons. ${ }^{23}$ In that case the release depends on export of adenosine via the equilibrative nucleoside transporters.

Since astrocytes can contact thousands of synapses and coordinate synaptic networks, ${ }^{8,24}$ it is conceivable that astrocytic release of ATP and its subsequent degradation into adenosine has a major regulatory function in setting a global adenosine-mediated inhibitory tone within a neuronal network. In addition, other glial cells can also contribute. For example, in retinal tissue, stimulation of glial cells leads to an adenosine-mediated inhibition of neuronal activity, but in this case Muller cells rather than astrocytes appear to be most important. $^{25}$

The distribution of adenosine formed from breakdown of released ATP will obviously also depend on the distribution of the enzymes that degrade the nucleotide. It was shown long ago that 5 'nucleotidase tended to accumulate in areas of a lesion, ${ }^{26}$ and we now know that CD73, the ecto5 'nucleotidase, is highly expressed in microglial cells, as is the ecto-NTPDase (nucleoside triphosphate diphosphohydrolase), CD39. ${ }^{27}$

Elimination of adenosine via astrocytic adenosine kinase. Several lines of evidence indicate that astrocytic ADK is the key regulator for ambient levels of adenosine: (i) In adult brain, ADK is predominantly expressed in astrocytes; $^{10}$ (ii) pharmacological inhibition of ADK is sufficient to prevent seizures in various models of epilepsy; ${ }^{28}$ (iii) genetic knockout or knockdown of ADK in cultured cells induces secretion of adenosine into the medium; ${ }^{29-32}$ (iv) transgenic overexpression of ADK triggers seizures by reduction of ambient adenosine; ${ }^{33}$ (v) inhibition of ADK in hippocampal slices increases endogenous adenosine and depresses neuronal firing, whereas inhibition of ADA had no effect; ${ }^{34}$ (vi) a substrate cycle between AMP and adenosine, which involves ADK and $5^{\prime}$-nucleotidase, enables minor changes in ADK activity to rapidly translate into major changes in adenosine; and ${ }^{35}$ (vii) ADK activity is regulated in response to brain injury and is subject to developmental regulation. ${ }^{10,36,37}$ Based on these considerations, and based on the lack of a classical transporter-regulated reuptake system for adenosine and the ubiquitous presence of bidirectional equilibrative nucleoside transporters, ${ }^{38}$ ADK likely fulfills the role of a metabolic reuptake system for adenosine. Thus, tight regulation of ADK expression levels and of its specific activity becomes a necessity. Therefore, it is not surprising that ADK is highly conserved in evolution, that no naturally occurring mutations of the Adk gene are known, and that a genetic disruption of the Adk gene is lethal., ${ }^{5,39}$

The fact that astrocytic ADK is of critical importance in regulating extracellular adenosine concentrations implies that the nucleoside transporters that facilitate adenosine uptake into astrocytes are important. Astrocytes express one concentrating (sodium dependent) and two equilibrative nucleoside transporters. ${ }^{40}$ Inhibition of this transport could potentially be used to elevate brain adenosine levels under conditions where extracellular adenosine is derived from extracellular ATP, but they would be less useful under conditions when adenosine is derived from intracellular production. ${ }^{41}$ It is interesting to note that cannabinoids can block the equilibrative transporter and this effect can partly explain the immunosuppressive effects of these compounds. ${ }^{42}$ The central role of astrocytes in regulating extracellular levels of adenosine is demonstrated in Figure 1.

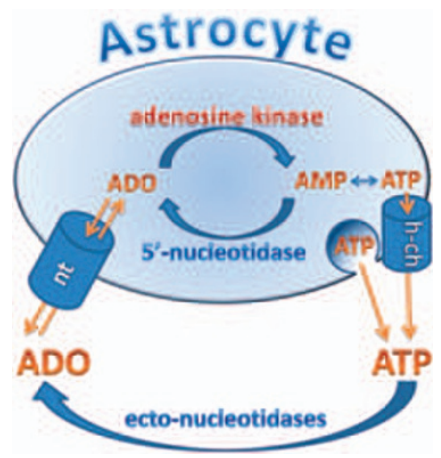

Figure 1 Extracellular adenosine levels are thought to be regulated by an astrocyte-based adenosine cycle. Astrocytes can release ATP via vesicular release and/or by direct release through hemichannels ( $h$-ch). Extracellular ATP is rapidly degraded into adenosine (ADO) by a series of ectonucleotidases. Adenosine can also be released directly via equilibrative nucleoside transporters (nt). Intracellularly adenosine levels are largely controlled by adenosine kinase, which is part of a substrate cycle between adenosine and AMP. Small changes in adenosine kinase activity rapidly translate into major changes in adenosine. Intracellular adenosine kinase is considered to be a metabolic reuptake system for adenosine. Only selected mechanisms and pathways are shown; for details please refer to the main text 


\section{Glial Adenosine Receptors}

There are four types of evolutionarily conserved and pharmacologically well-characterized adenosine receptors (ARs) called $A_{1}, A_{2 A}, A_{2 B}$, and $A_{3}{ }^{43}$ (Figure 2). Adenosine is the endogenous agonist at all these receptors, but at $A_{1}$ and $A_{3}$ receptors inosine can act as a partial agonist. ${ }^{44,45}$ The $A_{1}$ and $A_{3}$ receptors couple to the $G_{i}$ family of $G$ proteins and, thus, stimulate $\mathrm{K}^{+}$channels, reduce transient voltagedependent $\mathrm{Ca}^{2+}$ channels, and inhibit cAMP formation; $\mathrm{A}_{2 \mathrm{~A}}$ receptors couple to members of the $G_{S}$ family $\left(G_{\text {olf }}\right.$ in striatal neurons), whereas $A_{2 B}$ receptors couple to many $G$ proteins including $\mathrm{G}_{\mathrm{s}}, \mathrm{G}_{\mathrm{q}}$, and $\mathrm{G}_{12}$. Adenosine is approximately equipotent on $A_{1}, A_{2 A}$, and $A_{3}$ receptors, whereas $A_{2 B}$ receptors require higher agonist concentrations, if cAMP changes is the readout, ${ }^{45}$ but if microtubule associated protein (MAP) kinase activation is used to measure receptor activation adenosine is virtually equipotent on all four receptors. ${ }^{46}$ All four ARs are detected in astrocytes, ${ }^{22}$ and all have been reported to be expressed in microglial cells or microglial cell lines. ${ }^{47-49}$

$A_{1}$ receptors. $A_{1}$ receptors on astrocytes reduce their proliferation rate in culture. ${ }^{50}$ As in many other types of cells, activation of $A_{1}$ receptors can not only decrease cAMP accumulation but also stimulate phospholipase $C$, especially if this pathway is simultaneously activated by other stimuli. ${ }^{51-53}$ $A_{1}$ receptors help protect astrocytes from damage and cell death, ${ }^{22,54,55}$ partly via activation of PI3K and Erk 1/2 phosphorylation.

Nerve activity promotes myelination and it has been shown that this response is dependent on ATP, ${ }^{56}$ but ATP acts on oligodendrocytes indirectly, because ATP acts on astrocytes to release leukemia inhibitory factor. This response may be modified by adenosine, as $A_{1}$ receptors are present in oligodendroglia ${ }^{57}$ and stimulate their migration. It has been shown that $A_{1}$ receptor activation leads to white matter loss,

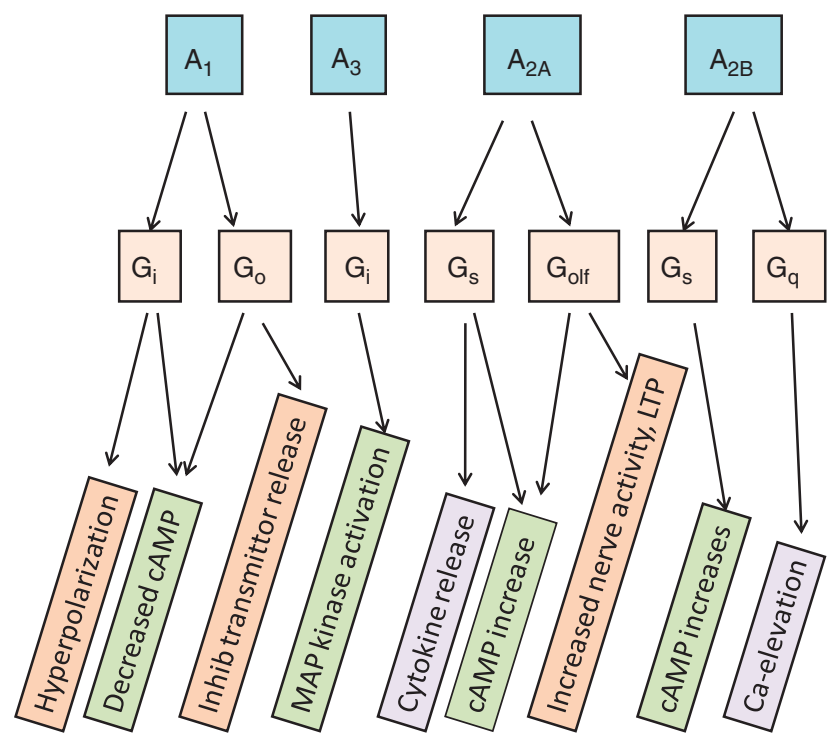

Figure 2 ARs, their coupling to G-proteins, and some of the downstream consequences of receptor activation and that $A_{1}$ receptors contribute to hypoxia-induced white matter loss. ${ }^{58} A_{1}$ receptors on microglial cells are reported to reduce excessive activation of microglial cells upon immune activation. $^{59}$ Activation of these microglial receptors may secondarily affect oligodendroglial cells ${ }^{59}$ and also astrocyte proliferation, ${ }^{60}$ which emphasizes the possibility of an extended glial network of signaling. $A_{1}$ receptors on neurons (especially at nerve terminals) are critically important in mediating the dampening effect on neuronal activity mediated by adenosine generated from ATP released from astrocytes. ${ }^{6,61}$ The highly abundant $A_{1}$ receptors at nerve endings may preferentially signal via $G_{0}$ proteins to inhibit transient calcium channels, whereas the same receptors in nerve cell bodies and dendrites may preferentially regulate potassium channel conductance via $\mathrm{G}_{1}$ proteins.

$A_{2 A}$ receptors. In brain, $A_{2 A} R s$ are expressed at high levels in striatal neurons and at low levels in neurons outside of the striatum and in glial cells. ${ }^{62,63}$ Many functional measurements (such as cAMP levels and cytokine release) coupled with pharmacological tools have clearly demonstrated the presence and function of $A_{2 A} R s$ in glial cells. ${ }^{64} A_{2 A} R$ binding densities are at the range $\sim 30-60 \mathrm{fmole} / \mathrm{mg}$ protein in primary cultured microglial cells or in sorted microglial cells derived from striatum, as estimated by ${ }^{3} \mathrm{H}$-ligand binding studies. ${ }^{65,66}$ Furthermore, the expression of the $A_{2 A} R$ in glial elements in both the striatum and the solitary tract is confirmed by electronmicroscopic studies. ${ }^{63,67}$ It should be noted that $A_{2 A} R$ expression in microglia and astrocytes is usually low under physiological conditions and frequently below the detection limit of histological methods (i.e., immunohistochemistry, autoradiography, or in situ hybridization). ${ }^{62,64,68}$

Importantly, expression of $A_{2 A} R s$ in glial cells is induced following brain insults. For example, LPS treatment induced $A_{2 A} R$ mRNA and protein in primary cultures of (mixed) glial cells (mainly in microglial cells) at $16 \mathrm{~h}$ and peaked at $48 \mathrm{~h}$ after the treatment. ${ }^{65}$ Recently, using double immunohistochemistry analysis, we demonstrated that $A_{2 A} R$ expression is induced in microglial cells and astrocytes of mouse substantia nigra at $24 \mathrm{~h}$ after 1-methyl-4-phenyl-1,2,3,6-tetrahydropyridine (MPTP) intoxication. The induction of $A_{2 A} R s$ in glial cells by brain insults and inflammatory signals, coupled with local increase in adenosine and proinflammatory cytokine levels (such as IL-1 $\beta$, which further induces $A_{2 A} R$ expression), may serve as part of an important feed-forward mechanism to locally control neuroinflammatory responses in the brain. It has been shown that adenosine, acting on $A_{2 A}$ receptors, can increase extracellular levels of glutamate, both by reducing glutamate uptake via GLT-1 and by direct release. ${ }^{69,70}$ Thus, some of the reported effects of $A_{2 A}$ receptors on glutamate release may be based on mechanisms mediated by astrocytes rather than by neurons.

$A_{2 A} R s$ in glial cells may exert complex actions on neuronal cell death (both, potentially deleterious as well as neuroprotective) and possibly other functions such as modulation of synaptic transmission. In astrocytes, activation of $A_{2 A} R s$ by extracellular adenosine increases astrocyte proliferation and activation, ${ }^{71,72}$ but inhibits the expression of iNOS and the production of $\mathrm{NO},{ }^{73}$ and regulates glutamate efflux by 
astrocytes. ${ }^{69}$ Thus, modulation of astrogliosis by $A_{2 A} R s$ is likely involved in brain repair processes, possibly via formation of tissue scar. In microglial cells, activation of $A_{2 A} R s$ has mixed effects on microglial proliferation, but has clear facilitating effects on the release of cytokines, including upregulation of cyclooxygenase 2 and release of prostaglandin E2 (PGE2), ${ }^{74}$ and on increases in nitric oxide synthase (NOS) activity and NO release ${ }^{65}$ and nerve growth factor expression. $^{75}$

$A_{2 B}$ receptors. It was shown early on that cyclic AMP accumulation in brain slices was due to an AR different than that responsible for adenylate cyclase stimulation in striatum, and it is now clear that a major part of the brain slice cAMP response is due to $A_{2 B}$ receptor activation on astrocytes. ${ }^{76}$ $A_{2 B}$ receptors can couple with two different classes of $G$ proteins, $G_{q}$ and $G_{s}$. $G_{q}$ regulates intracellular calcium and vesicular release, whereas $G_{s}$ affects a plethora of cAMPdependent signaling pathways. The $A_{2 B}$ receptor may also activate phospholipase $\mathrm{C}^{77}$ and appears to be responsible for the adenosine-induced stimulation of IL-6 from astrocytes. ${ }^{78}$ In airways, $A_{2 B}$ receptors, via $c A M P$, regulate chloride channels. ${ }^{79}$ Since this occurs also in the intestine, it is fair to predict that cells in the CNS likewise alter chloride flux via $\mathrm{A}_{2 \mathrm{~B}} \mathrm{R}$ signaling. In particular, the possibility exists that adenosine is an important regulator of astrocytic swelling via modulation of volume-regulated anion channels. $A_{2 B}$ receptors may also play an important role in the development of the nervous system; it was intially proposed that the important regulator, netrin, required signaling via $A_{2 B}$ receptors, ${ }^{80}$ but later studies showed that netrin does not require simulataneous $A_{2 B} R$ signaling, ${ }^{81}$ but that netrin signaling requires prior $A_{2 B}$ activation because the receptor is thereby regulated. ${ }^{82}$

$A_{3}$ receptors. Astrocytic $A_{3}$ receptors appear to regulate chemokine release. ${ }^{83}$ Activation of $A_{3}$ receptors by endogenous adenosine protects astrocytes from cell death induced, for example, by hypoxia. ${ }^{22}$ Microglial cells have functional $A_{3}$ receptors coupled to MSAP kinase and p38 signaling. ${ }^{47,84}$ Although adenosine itself has little effect on microglial migration, it was shown that migration induced by ATP, ${ }^{85}$ perhaps predominantly via $\mathrm{P} 2 \mathrm{Y} 12$ receptors, ${ }^{86}$ is lost when ATP hydrolysis via CD39 is eliminated, and can be restored by adenosine. ${ }^{27}$ Although it is not absolutely certain that the relevant $A R$ is the $A_{3} R$, it is tempting to speculate that there is a similarity to the situation in neutrophil leucocytes where ATP acting on a P2Y receptor acts in concert with adenosine acting on $A_{3}$ receptors to stimulate migration. ${ }^{87}$ Microglial cells (and $A_{3}$ receptors) may also be of particular importance in the regulation of chemokine release and chemokine actions. ${ }^{88}$

\section{Glial Cells and Neurovascular Coupling}

Glial cells play important roles in coupling neuronal function to the cerebral microvasculature that controls cerebral blood flow (CBF), ${ }^{89,90}$ in the sense that increased neuronal activity requires corresponding increases in CBF. Apart from large processes that stain for intermediate filaments and give astrocytes their stellar appearance, astrocytes have a multitude of fine processes that have little overlap with processes from other astrocytes and that define individual astrocytic domains, which each contain 300-600 neuronal dendrites and $10^{5}$ synapses in rodent hippocampus. ${ }^{8,91-93}$ Thus, a single astrocyte can sense the activity, and integrate the function, of hundreds of neurons within its domain. In addition, each astrocyte extends at least one process with endfeet surrounding blood vessels of the microvasculature. Therefore, astrocytes are uniquely located to adjust regional CBF to regional energy metabolism.

The vasodilator adenosine has been identified as an important mediator that couples CBF to neuronal activation. ${ }^{94}$ Thus, adenosine was demonstrated to mediate glutamateinduced vasodilation in the cerebral cortex. ${ }^{95,96}$ Topical application of glutamate dilated pial arterioles, an effect that could be reversed by an $A_{2 A} R$ antagonist, but not by an $A_{2 A} R$ antagonist. $^{95}$ Likewise topical superfusion AMPA on the cortical surface through a closed cranial window resulted in increases in pial arteriolar diameter, an effect that could be reversed by $A_{2 A}$ and $A_{2 B} R$ blockade, but not by inhibition of NO synthase, cyclooxygenase-2, or cytochrome $P-450$ epoxygenase. ${ }^{96}$ Apart from the activation of vascular ARs, adenosine can exert important regulatory functions by activation of astrocytic ARs. ${ }^{97}$ Thus, the adenosine-evoked calcium response in acutely isolated astrocytes was found to be coupled to the $A_{2 B}$ receptor; ${ }^{77}$ based on these findings adenosine could be implicated in promoting the propagation of calcium increases throughout astrocytic processes. Increased $\mathrm{Ca}^{2+}$ in turn is also associated with the release of ATP through connexin hemichannels, a process that is potentiated by $A_{2 B} R$ activation. ${ }^{98,99}$ Through these mechanisms ATP release and degradation into adenosine via ectonucleotidases appears to mediate arteriolar dilation in response to neuronal activation. ${ }^{100}$ This process was dependent on astrocytes, since application of the selective gliotoxin, L-AAA, led to complete loss of arteriolar dilation in response to neuronal activation. ${ }^{101}$

\section{Glial Control of Glutamate and Excitotoxicity}

Astrocytes play a fundamental role in the pathogenesis of ischemic neuronal death. ${ }^{102}$ A large body of evidence indicates that astrocytes are involved in the control of glutamate homeostasis and susceptibility of the brain to excitotoxic injury. ${ }^{103}$ Glutamate transporters are expressed in many different types of brain cells, but astrocytes are primarily responsible for glutamate uptake. Studies using genetic deletion or antisense oligonucleotides-mediated knockdown of the astroglial glutamate transporter GLT-1 have demonstrated that this transporter is the predominant subtype responsible for the clearance of extracellular glutamate in the brain. ${ }^{104,105}$ Affected animals were highly susceptible to glutamate-dependent excitotoxicity and developed epileptic seizures. ${ }^{104,105}$ After uptake of glutamate into astrocytes, the enzyme glutamine synthetase converts glutamate into glutamine, which is then transported into neurons where it is converted back into glutamate. Interestingly, a loss of glutamine synthetase was found in the sclerotic hippocampus of human patients with temporal lobe epilepsy ${ }^{106}$ and the 
authors of that study concluded that reduced activity of the glutamate-glutamine cycle led to accumulation of extracellular glutamate.

Apart from the mechanisms described above, astrocytes themselves can be a significant source of extracellular glutamate, which can be released by a variety of mechanisms. ${ }^{107}$ It has been demonstrated that $\mathrm{Ca}^{2+}$ elevations in astrocytes induce the excitotoxic release of glutamate from these cells. ${ }^{108}$ Most importantly, the $\mathrm{Ca}^{2+}$-dependent astrocytic release of glutamate was also dependent on the vesicular glutamate transporters (VGLUT1/2) and the vesicular SNARE protein, cellubrevin, and was consistent with a vesicular release mechanism of glutamate that was similar to synaptic release of glutamate. ${ }^{108}$ Finally, it was shown that astrocyte-derived glutamate targets synaptic $\mathrm{N}$-methyl-Daspartic acid (NMDA) receptors, ${ }^{109}$ providing a rational explanation for the astrocyte-based control of neurotoxicity. Given the emerging roles of astrocytes in the control of neuronal excitotoxicity, neuroprotective efforts targeting the functional integrity of astrocytes may constitute a superior strategy for future neuroprotection.

\section{Novel Methods for Studying the Role of Glia}

Co-culture of glia and neurons. Many original insights into gliotransmission were discovered using co-culture systems and then extended to brain slices or the intact brain. For example, the first evidence for gliotransmission came from studies of mixed cultures of astrocytes and neurons demonstrating that experimentally evoked $\mathrm{Ca}^{2+}$ elevation in astrocytes evoked elevation of $\mathrm{Ca}^{2+}$ in adjacent neurons. ${ }^{110,111}$ In this method, cultured cells from postnatal day 1-4 rodent brain are first enriched with one population of either glial or neuronal origin using specific culture conditions and then confirmed by immunohistochemistry. Glial or neuronal cells are then plated separately or together onto a coated substrate. The distinct morphology of glial cells and neurons allows identification of these distinct cell types and permits direct application of electric field potentials, micropipette tips, or neurochemical substrates to astrocytes in order to evoke a specific elevation of calcium in glial cells (e.g., in astrocytes). ${ }^{110,111}$ The spatiotemporal control over mechanical stimuli has permitted the selective stimulation of single astrocytes in mixed cultures of rat forebrain astrocytes and neurons. Using this strategy it was demonstrated that the elevation of calcium, triggered by focal electric field potentials in single astrocytes, induced a wave of calcium increase that was propagated from astrocyte to astrocyte, and importantly, this wave of calcium increase also evoked large increases in the concentration of cytosolic calcium in neurons depending on those astrocytes. ${ }^{110,111}$ More recently, mixed co-cultures in multi-compartment dishes were equipped with the capability to provide electronic stimuli selectively to neurons in mixed cultures of oligodendrocytes and dorsal root ganglion neurons. This approach led to the finding that ATP and adenosine, released from neurons, act as potent neuron-glial transmitters that inhibited oligodendrocyte progenitor cell proliferation, stimulated their differentiation, and promoted the formation of myelin. ${ }^{56,112}$
Transgenic overexpression and targeted knockout of genes in defined glial populations. Glial cells have been shown to release gliotransmitters, including ATP, 9,17 glutamate, ${ }^{111,113}$ and $\mathrm{D}$-serine, ${ }^{114}$ to coordinate synaptic networks. However, neurons and glia share these same chemical signaling molecules, making it difficult to define the role of gliotransmitters. To molecularly dissect the role of glial signaling molecules, genetic approaches have been developed to selectively manipulate the SNARE-dependent release of gliotransmitters using a glia-specific promoter. Pascual and Haydon developed a transgenic mouse line, which uses the tet-off system to allow conditional expression of the cytosolic portion of the SNARE domain of synptobrevin-2 [dominant-negative SNARE (dn-SNARE)] selectively in astrocytes. ${ }^{15}$ The selective expression of dn-SNARE was achieved by the use of an astrocytespecific glial fibrillary acid protein promoter. To confirm the cell type selectivity of astrocytic transgene expression, Pascual and co-workers used enhanced green fluorescent protein (EGFP) as a reporter system and showed that EGFP was visually detectable in $97 \%$ of the dn-SNARE-transgeneexpressing cultured astrocytes, and that EGFP-positive cells colocalized specifically with the astrocytic marker, but not with neuronal, NG2-glial, or oligodendroglial markers. This transgenic line has been used successfully to demonstrate the functional significance of gliotransmission on synaptic plasticity in hippocampus, ${ }^{15}$ and more recently in the sleepwake cycle. ${ }^{61}$ Similarly, transgenic overexpression of a mutant disease-causing gene in a defined glial cell population has been used to study the role of superoxide dismutase-1 (SOD1) in astrocytes in the development of motor neuron death. Nagai et al. ${ }^{115}$ demonstrated that the astrocyte-selective expression of mutant human SOD1 (but not in spinal motor neurons, microglia or fibroblasts) killed spinal primary and embryonic mouse stem cell-derived motor neurons.

As a complementary genetic approach, the selective deletion of signaling molecules in defined glial cell populations can be accomplished using the Cre-loxP strategy. For example, Boillee et al. ${ }^{116}$ generated a transgenic line (LoxSOD1 ${ }^{\text {G37R }}$ ) that carried a mutant human SOD1 gene flanked at both ends by a 34-bp LoxP sequence. These 'floxed' mice were then cross-bred to two transgenic lines with expression of the Cre protein under control of (i) the promoter from the Islet-1 transcription factor, which directs the expression exclusively in progenitors of motor and dorsal root ganglion neurons, and (ii) the CD11b promoter, which directs the expression exclusively in the myeloid lineage (including macrophages and microglial cells). The establishment of these two novel transgenic lines allowed to demonstrate that the SOD1 mutation in motor neurons and microglial cells contributes distinctly to the onset and progression of amyotrophic lateral sclerosis: whereas expression of SOD1 in motor neurons is the primary signal for the initiation of motor neurodegeneration and an early sign of disease progression, the genetic inactivation of SOD in microglial cells had little effect on the early disease phase, but markedly attenuated disease progression. ${ }^{116}$ Thus, these genetic approaches to selectively manipulate signaling molecules in defined glial (or neuronal) populations provide 
critical insights into the distinct role of glial cells in the development of neurodegeneration.

Flow cytometric analysis and FACS. The structural complexity of brain tissues hampers the dissection of unique roles of glial cells under various physiological and pathological conditions. Glial cells are characterized by a unique morphology, which permits distinction of neuronal versus glial cells in intact brain by immunohistochemistry. However, it is difficult to quantify immunohistochemical changes without performing labor-intensive stereological analysis. Furthermore, there is a critical need to isolate large numbers of pure glial cells from intact brain for detailed molecular analysis such as qPCR and microarray analysis. Flow cytometric and fluorescence-activated cell sorting (FACS) can be adapted to partially circumvent these limitations for the study of glial cell functions in brain.

In the first application, defined glial cell populations (such astrocytes, microglia, or oligodendrocytes) are identified by labeling with a fluorescent antibody directed against specific cell-surface markers. Quantitative changes of glial populations in normal and injured brains are determined by flow cytometry. For example, we recently used this analysis to evaluate the change of CD11b + (a cell-surface marker for microglial cells) and GFAP + (a maker for astrocytes) cells in mouse striatum after treatment with MPTP and the $A_{2 A} R$ antagonist KW6002. ${ }^{117}$ This analysis not only provided an improved quantitative assessment of the effect of the $A_{2 A} R$ antagonist on microglial activation at the very early phase of MPTP intoxication, but also identified a specific microglial cell population (i.e., CD11b + cells with a large cell size representing fully activated microglial cells), which are most sensitive to KW6002 treatment in the brain. ${ }^{117}$

In the second application, FACS permits isolation and purification of distinct populations of glial cells from neurons from brain tissues using fluorescent antibodies directed against cell-surface markers. The sorted glial cell populations can then be used for detailed molecular analyses such as quantitative PCR and microarray analysis. For example, Lovatt et al. ${ }^{118}$ successfully performed microarray profiling of sorted astrocytes from mouse cortex using FACS and (surprisingly) demonstrated that most enzymes in the tricarboxylic acid cycle are expressed at higher relative levels in astrocytes than in neurons.

\section{Adenosine Signaling in Glial Cells, Excitotoxicity, and Cell Death}

As outlined above, synaptic levels of adenosine are largely controlled by an astrocyte-based adenosine cycle and the activity of the astrocyte-based enzyme ADK. Consequently, adenosine signaling in glial cells effects excitotoxicity and cell death in a variety of experimental paradigms. In addition, several forms of brain insult activate microglial cells. Here, ATP release is critically important, ${ }^{85}$ but the ATP response in microglial cells is markedly enhanced by adenosine generated from ATP. ${ }^{27}$

Epilepsy. The adenosine kinase hypothesis of epileptogenesis implies that dysregulation of ADK is a major contributing factor to the epileptogenic cascade ${ }^{12}$ (Figure 3). Consequently, ADK expression levels (that determine levels of ambient adenosine) determine the brain's susceptibility to acute seizure-induced cell death. Mice with only moderate transgenic overexpression of ADK in the brain ( $141 \%$ of normal) were highly susceptible to acute seizure-induced cell death and did not survive beyond 3 days following status epilepticus, ${ }^{37}$ whereas engineered mice with reduced levels of ADK in the forebrain $(62 \%$ of normal) were completely resistant to seizure-induced cell death. ${ }^{37}$ Resistance to seizure-induced excitotoxic cell death in ADK-deficient mice was dependent on adenosine and increased adenosine $A_{1} R$ activation, since blockade of $A_{1} R s$ with its selective antagonist 8-cyclopentyl-1,3dipropylxanthine restored wild-type-like seizure-induced excitotoxic cell death. ${ }^{37}$

Astrogliosis is a pathological hallmark of the epileptic brain and contributes to seizure generation by a variety of mechanisms. ${ }^{12,119,120}$ A recent study in our laboratory has identified the enzyme ADK in astrocytes as a molecular link between astrogliosis and neuronal dysfunction in epilepsy. ${ }^{37}$ In a mouse model of CA3-selective epileptogenesis, we found spatio-temporal colocalization of astrogliosis, upregulated ADK, and focal spontaneous electrographic seizures that were all restricted to the CA3 region, the site of the epileptogenesis precipitating acute injury; importantly, seizures could be suppressed pharmacologically by ADK inhibition. ${ }^{37}$ In this model, the seizures remained highly localized and restricted to the astrogliotic scar, presumably due to normal adenosinergic control of the surrounding brain tissue. Transgenic overexpression of ADK, as well as genetic disruption of the $A_{1} R$, was sufficient to trigger spontaneous seizures, indicating that adenosine dysfunction rather than astrogliosis per se was responsible for seizure generation. ${ }^{121}$

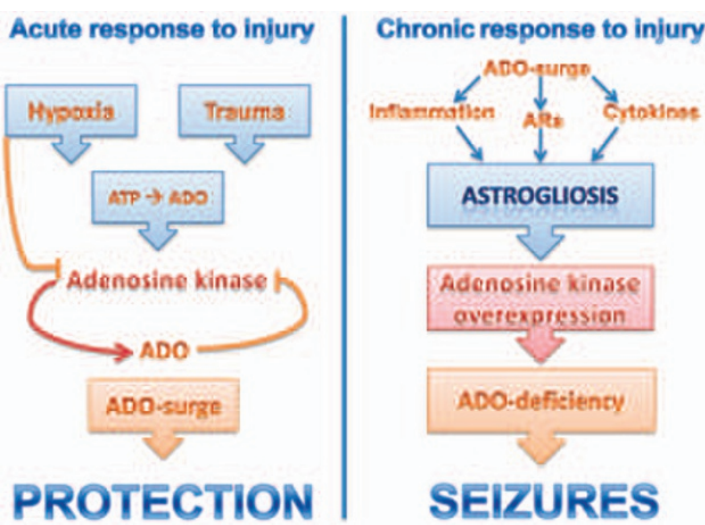

Figure 3 Role of the adenosine (ADO)/ ADK system in regulating acute and chronic responses to injury. Left: Within hours after brain injury (e.g., stroke, trauma, prolonged seizures) a surge in micromolar levels of ADO results that protects the brain from further injury and from seizures. Hypoxia and trauma can directly lead to a rise in extracellular ATP that is rapidly degraded into adenosine. High levels of adenosine are known to inhibit ADK, further amplifying the adenosine surge. Right: The acute adenosine surge contributes to trigger astrogliosis via a variety of mechanisms that include modulation of astrocytic ARs, modulation of inflammatory processes, and release of cytokines. Astrogliosis leads to overexpression of ADK, resulting in adenosine deficiency, which contributes to seizure generation 
Conversely, mice with genetically induced reduction of ADK in forebrain were completely resistant to the development of spontaneous seizures. ${ }^{37}$ In vitro studies performed on hippocampal slices have subsequently demonstrated that reduction of the basal tone of adenosine by ADK is permissive to seizure generation, whereas ADK did not limit activitydependant adenosine release. ${ }^{122}$ Together, these findings provide a neurochemical rationale for adenosine augmentation therapies (AATs). Consequently, several focal AATapproaches, based on intracerebral adenosine-releasing implants, have demonstrated robust anticonvulsive and, possibly, antiepileptogenic efficacy in a variety of experimental paradigms that have been reviewed elsewhere. ${ }^{123,124}$

Traumatic brain injury. Traumatic brain injury triggers an acute surge in adenosine, presumably as a consequence of ATP release, and this may represent an endogenous neuroprotective mechanism. In one study, adenosine levels increased 61-fold following controlled cortical impact (CCI) in rats and peaked at 20 min following the impact. ${ }^{125}$ The existence of an endogenous protective action of adenosine at $A_{1}$ receptors early after experimental TBI was further corroborated by the finding of lethal status epilepticus in $A_{1}$ R-knockout mice subjected to either controlled cortical impact. $^{126}$ or to kainic acid-induced hippocampal injury. ${ }^{127}$ In contrast to $A_{1} R$-knockout mice, $A_{2 A} R$-knockout mice were largely protected from the adverse effects of $\mathrm{CCl}^{128}$ In line with these findings, increases in cerebrospinal fluid caffeine concentration were associated with favorable outcome after severe traumatic brain injury in humans, likely due to caffeine-mediated inhibition of $A_{2 A} R s .{ }^{129}$ Likewise, chronic, but not acute, caffeine attenuated the consequences of TBI in the mouse $\mathrm{CCl}$ model. ${ }^{130}$ Although it probably does not contribute to the surge in adenosine following brain injury, acute downregulation of ADK in astrocytes has been described as a consequence of stroke ${ }^{36}$ or acute seizures, ${ }^{131}$ and this may prolong the adenosine increase.

Parkinson's disease. The adenosine $A_{2 A}$ receptor is a leading non-dopaminergic therapeutic target in Parkinson's disease (PD) (Figure 4). Interest in this receptor within the context of PD derives primarily from two lines of experimental and clinical investigations: first, decade-long preclinical studies demonstrated a unique colocalization of $A_{2 A} R s$ and dopamine $D_{2} R s$ in striatopallidal neurons. Antagonistic interactions between $A_{2 A} R s$ and $D_{2} R s$ at the molecular, neurochemical, and behavioral level explain the motorstimulant effects of $A_{2 A} R$ blockade. ${ }^{132-134}$ Thus, $A_{2 A} R$ antagonists, such as $\mathrm{KW}-6002$ (istradefylline) and $\mathrm{SCH} 420814$, have now completed clinical phase IIB-III trials. Despite some limitations of these clinical trials and admittedly modest effects ('OFF' time reduced by one hour), these studies confirm that selective $A_{2 A} R$ antagonists can stimulate motor activity by potentiating the L-dopa effect in advanced PD patients. ${ }^{135,136}$ Second, in addition to symptomatic relief, $A_{2 A} R$ antagonists appear to more directly attenuate dopaminergic neurodegeneration, as suggested by convergent epidemiological and experimental evidence. Following an initial report from the Honolulu Heart Program ${ }^{137}$ by Ross and co-workers, several large-cohort, prospective studies have confirmed a similar inverse relationship between the consumption of caffeinated coffee and the risk of developing PD. Including the Health Professionals' Follow-Up Study and the Nurses' Health Study these studies involved a total of 47351 men and 88565 women, ${ }^{138}$ whereas a more recent study conducted by the Finnish Mobile Clinic Health Examination Survey included 19518 men and women. ${ }^{139}$ These studies firmly established a relationship between increased caffeine consumption and decreased risk of developing PD in males. In addition, studies with animal models of PD provide a compelling clue about the potentially protective effects of caffeine, by demonstrating that pharmacological blockade (by caffeine or selective $A_{2 A} R$ antagonists) or genetic depletion of the $A_{2 A} R$ attenuates dopaminergic neurotoxicity and neurodegeneration. ${ }^{140-142}$ These studies provide a neurobiological basis for the inverse relationship between increased caffeine consumption and reduced risk of developing PD.

Despite consistent demonstration that $A_{2 A} R$ antagonists afford neuroprotection against MPTP or 6-hydroxydopamineinduced dopaminergic neurotoxicity, the mechanism by which $A_{2 A} R$ inactivation protects against the loss of dopaminergic neurons remains unknown. The particular challenge lies in

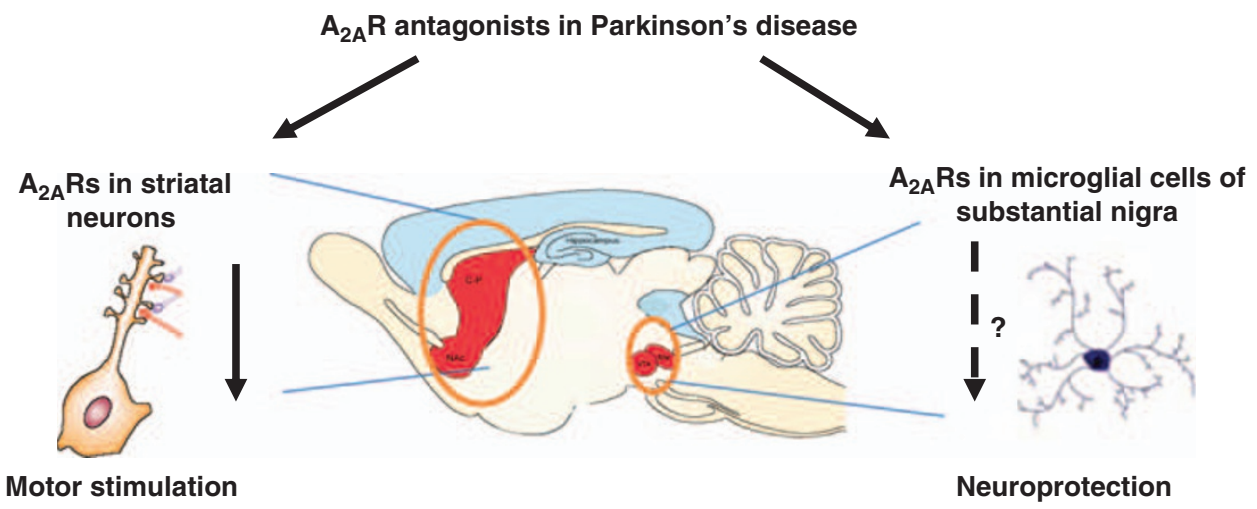

Figure 4 The dual functions of $A_{2 A} R$ antagonists in PD models: $A_{2 A} R$ antagonists act at the $A_{2 A} R$ in striatal neurons to stimulate motor activity. Furthermore, it is postulated that $A_{2 A} R$ antagonists may modulate microglial activation in substantia nigra to exert a possible neuroprotective effect in an animal model of PD 
explaining the apparent dichotomy between restricted expression of the $A_{2 A} R$ in striatopallidal neurons and neuroprotection against degeneration of dopaminergic neurons in the substantia nigra where only a scattered expression of $A_{2 A} R s$ is detected. An additional challenge is to identify the cellular mechanism, which allows $A_{2 A} R$ inactivation to protect neurons against a broad spectrum of brain insults, from ischemia to excitotoxicity to mitochondrial toxicity. ${ }^{143}$ In this context, the involvement of the glial $A_{2 A} R$ becomes an attractive possibility, since glial function and neuroinflammation is commonly associated with diverse pathological conditions as mentioned above. Indeed, we recently demonstrated that MPTP treatment markedly upregulates $A_{2 A} R$ expression in microglial cells at $24-48 \mathrm{~h}$ after treatment, ${ }^{65,66}$ which may result in further amplification of the $A_{2 A} R$-mediated modulation of neuroinflammation in PD models. Consistent with this notion, an immunohistochemical study showed that $\mathrm{KW}-6002$ reduced the loss of striatal dopamine contents and nigral cell bodies, and this coincided with inhibition of microglial activation. ${ }^{144}$ Furthermore, we demonstrated by flow cytometry that KW-6002 attenuated MPTP-induced microglial activation at $48 \mathrm{~h}$ after MPTP treatment. ${ }^{117}$ In conclusion, $A_{2 A} R$ antagonists may confer neuroprotection by acting at $A_{2 A} R s$ in glial cells, at least in the MPTP model of PD.

Ischemia. During ischemia an imbalance between ATP degradation and resynthesis brings about a rapid and marked increase in extracellular level of adenosine in the brain during ischemia. ${ }^{145-154}$ In addition hypoxia will increase ATP release, resulting in further adenosine production. Although no clinical reports with purinergic compounds in human stroke exist, it is widely believed that adenosine and its receptors function as an endogenous neuroprotectant under these conditions. ${ }^{155-161}$ Indeed, adenosine ${ }^{162}$ or adenosine-potentiating agents (such as inhibitors of ADA or ADK, ${ }^{163-167}$ or of adenosine transport ${ }^{151,166,168-173}$ ) offer protection against ischemic neuronal damage in different in vivo ischemia models. Furthermore, transgenic overexpression of ADK aggravates cell death, whereas reduction of ADK level in the hippocampus increases protection after transient focal ischemia. ${ }^{36,174}$

Such a protective effect is attributed to stimulation of adenosine $A_{1}$ receptors that exert a protective role in ischemia by presynaptic reduction of $\mathrm{Ca}^{2+}$ influx, by inhibition of the release of excitatory neurotransmitters, ${ }^{175,176}$ and by postsynaptic hyper-polarization and reduction of neuronal activity through increases in $\mathrm{K}^{+}$and $\mathrm{Cl}^{-}$ion conductances. ${ }^{177}$ The efficacy of $A_{1}$ receptor stimulation on neuroprotection depends on the model used and no protective effect was observed in a global ischemia model. ${ }^{178}$ Since adenosine does influence glutamate release, it is suggested that this is not critically important in some ischemic models. However, adenosine (probably acting at the $A_{2 A}$ receptor) may in fact contribute to neurotoxicity, neuronal damage, and cell death. The potential neuroprotection by $A_{2 A} R$ antagonists was first reported in a global ischemia model with the less selective antagonist CGS 15943. ${ }^{179,180}$ Further studies substantiated this finding in different models of ischemia with the selective $A_{2 A}$ receptor antagonist 8-(3-chlorostyryl)caffeine (CSC) and $\mathrm{SCH} 58261^{181,147,182}$ in various animal models of stroke. ${ }^{183,184}$ Studies of genetically manipulated mice confirmed the neuroprotective role of $A_{2 A}$ receptor antagonists on ischemic brain damage. ${ }^{185}$ Major protective effects of $A_{2 A}$ receptor antagonists in stroke have been attributed to reduced glutamate outflow. ${ }^{183,186,187}$ It should be considered however, that in several studies, $A_{2 A}$ receptor agonists have been found protective in the global ischemia model in the gerbil $^{180}$ and that $A_{2 A}$-knockout mice show aggravated hypoxic ischemic injury in neonatal mice. ${ }^{188}$ Possible mechanisms are not clear yet, but include $A_{2 A} R$-mediated protection via inhibition of platelet aggregation, vasodilation, ${ }^{163,189}$ or anti-inflammatory actions. Lastly, activation of $\mathrm{A}_{3} \mathrm{Rs}$ produced mixed results and the exact contribution of $A_{3} R s$ to ischemic brain injury is not clear. ${ }^{190}$

So far, support for a role for glia in the neuroprotective effect of $A_{2 A} R$ antagonism in ischemia comes from the observation that the $A_{2 A}$ receptor antagonist $\mathrm{SCH} 58261$ reduces p38 MAPK activation in microglial cells ${ }^{184}$ and phospho-JNK in neurons and oligodendrocytes ${ }^{191}$ in the ischemic hemisphere $24 \mathrm{~h}$ after permanent MCAO. Since p38 MAPK and JNK are activated up to $24 \mathrm{~h}$ after ischemia ${ }^{192,193}$ and are involved in neuronal death, ${ }^{194,195}$ this correlation indicates that $A_{2 A} R$ antagonists may confer neuroprotection against ischemic brain injury through modulation of glial function and neuroinflammation. However, reduced MAPK activation might be secondary to a reduction in the excitotoxic cascade that primes p38 and JNK activation, since reduction glutamate outflow in the ischemic brain by $A_{2 A} R$ blockade is believed to be one of the main underlying mechanisms. ${ }^{196}$ Further studies with selective manipulation of glial ARs or glial function in vivo are critical to our understanding to what extend adenosine regulation of glial signaling and function is responsible for ischemic brain injury.

\section{Conclusions and Major Open Questions}

The discussion above has shown that much is now known about a role of glial cells in mediating the effects of adenosine (and other purines) in different neurodegenerative states. It is clear that many of the actions of endogenous or exogenous adenosine (and ATP) are in fact due to actions on glial cells. This makes it much more complicated to understand precisely how adenosine acts, and it has become apparent that the often diverse actions reported are due to the fact that several different receptors, located on many cell types, are involved. In order to get a better understanding, there are several major questions that require an answer. Among the questions that need to be addressed in future research we find:

1. Is the acute adenosine surge that follows brain injury a trigger for subsequent astrocyte activation?

2. Do all the proposed mechanisms of ATP release from glial cells in fact occur, and are the triggers for astrocytic ATP release via these mechanisms different?

3. To what extent does regional variation in the expression of ecto-nucleotidases control the distribution of adenosine in brain?

4. Can adenosine signals propagate within the brain via astrocyte-astrocyte communication? 
5. Given the major increase in glial cells in humans, how far can we extrapolate from rodents to man?

6. When several ARs, with at least partly opposing signaling, appear to regulate a single biological response, are the receptors located on different cells or on very different parts of the same cell?

7. Given that two GPCR molecules can form dimers, but apparently only one of them can actually signal, is there any functional significance of heterodimers between two types of purine receptors?

8. Can activation of endothelial cells at the vascular interphase signal to synapses?

9. Are microglial cells directly involved in synaptic transmission or do they mainly help prune synaptic contacts?

10. Why are effects of A2ARs on inflammation different in CNS and peripheral organs?

Acknowledgements. This work was supported by NIH Grants NS058780, MH083973, NS061844, NS057538, and NS057475, and by the CURE Foundation in collaboration with the Department of Defense (to DB), by NIH Grants NS48995, NS41083, and DA19362, and a grant from the Department of Defense W81XWH071-1-0012 (to JFC), and by grants from the Swedish Science Research Council and Hjärnfonden (to BBF).

1. Zipp $F$, Aktas $O$. The brain as a target of inflammation: common pathways link inflammatory and neurodegenerative diseases. Trends Neurosci 2006; 29: 518-527.

2. Geiger JD, Buscemi L, Fotheringham JA. Role of adenosine in the control of inflammatory events associated with acute and chronic neurodegenerative disorders In: Hasko G Cronstein BN, Szabo C (eds). Adenosine Receptors. Therapeutic Aspects for Inflammatory and Immune Diseases. Taylor and Francis: CRC, 2007 pp 213-236.

3. Di Virgilio $F$, Ceruti S, Bramanti $P$, Abbracchio MP. Purinergic signalling in inflammation of the central nervous system. Trends Neurosci 2009; 32: 79-87.

4. Zimmermann $\mathrm{H}$. Extracellular metabolism of ATP and other nucleotides. Naunyn Schmiedebergs Arch Pharmacol 2000; 362: 299-309.

5. Boison D. Adenosine kinase, epilepsy and stroke: mechanisms and therapies. Trends Pharmacol Sci 2006; 27: 652-658.

6. Martin ED, Fernandez M, Perea G, Pascual O, Haydon PG, Araque A et al. Adenosine released by astrocytes contributes to hypoxia-induced modulation of synaptic transmission. Glia 2007; 55: 36-45.

7. Halassa MM, Fellin T, Haydon PG. The tripartite synapse: roles for gliotransmission in health and disease. Trends Mol Med 2007; 13: 54-63.

8. Halassa MM, Fellin T, Takano H, Dong JH, Haydon PG. Synaptic islands defined by the territory of a single astrocyte. J Neurosci 2007; 27: 6473-6477.

9. Haydon PG, Carmignoto G. Astrocyte control of synaptic transmission and neurovascular coupling. Physiol Rev 2006; 86: 1009-1031.

10. Studer FE, Fedele DE, Marowsky A, Schwerdel C, Wernli K, Vogt K et al. Shift of adenosine kinase expression from neurons to astrocytes during postnatal development suggests dual functionality of the enzyme. Neuroscience 2006; 142: 125-137.

11. Boison D. Adenosine as a neuromodulator in neurological diseases. Curr Opin Pharmacol 2008; 8: 2-7.

12. Boison D. The adenosine kinase hypothesis of epileptogenesis. Prog Neurobio/ 2008; 84: 249-262.

13. Abbracchio MP, Burnstock G, Verkhratsky A, Zimmermann $\mathrm{H}$. Purinergic signalling in the nervous system: an overview. Trends Neurosci 2009; 32: 19-29.

14. MacDonald PE, Braun M, Galvanovskis J, Rorsman P. Release of small transmitters through kiss-and-run fusion pores in rat pancreatic beta cells. Cell Metab 2006; 4 283-290.

15. Pascual O, Casper KB, Kubera C, Zhang J, Revilla-Sanchez R, Sul JY et al. Astrocytic purinergic signaling coordinates synaptic networks. Science 2005; 310: 113-116.

16. Chen X, Wang L, Zhou Y, Zheng LH, Zhou Z. 'Kiss-and-run' glutamate secretion in cultured and freshly isolated rat hippocampal astrocytes. J Neurosci 2005; 25: 9236-9243.

17. Zhang Z, Chen G, Zhou W, Song A, Xu T, Luo $Q$ et al. Regulated ATP release from astrocytes through lysosome exocytosis. Nat Cell Biol 2007; 9: 945-953.

18. Kang J, Kang N, Lovatt D, Torres A, Zhao Z, Lin J et al. Connexin 43 hemichannels are permeable to ATP. J Neurosci 2008; 28: 4702-4711.

19. Iglesias R, Dahl G, Qiu F, Spray DC, Scemes E. Pannexin 1: the molecular substrate of astrocyte 'hemichannels'. J Neurosci 2009; 29: 7092-7097.
20. Liu HT, Sabirov RZ, Okada Y. Oxygen-glucose deprivation induces ATP release via maxi-anion channels in astrocytes. Purinergic Signal 2008; 4: 147-154.

21. Cocucci E, Racchetti G, Meldolesi J. Shedding microvesicles: artefacts no more. Trends Cell Biol 2009; 19: 43-51.

22. Bjorklund O, Shang MM, Tonazzini I, Dare E, Fredholm BB. Adenosine $A(1)$ and $A(3)$ receptors protect astrocytes from hypoxic damage. Eur J Pharmacol 2008; 596: 6-13.

23. Parkinson FE, Sinclair CJ, Othman T, Haughey NJ, Geiger JD. Differences between rat primary cortical neurons and astrocytes in purine release evoked by ischemic conditions. Neuropharmacology 2002; 43: 836-846.

24. Ventura R, Harris KM. Three-dimensional relationships between hippocampal synapses and astrocytes. J Neurosci 1999; 19: 6897-6906.

25. Newman EA. Glial cell inhibition of neurons by release of ATP. J Neurosci 2003; 23: $1659-1666$

26. Kreutzberg GW, Barron KD. $5^{\prime}$-Nucleotidase of microglial cells in the facial nucleus during axonal reaction. J Neurocytol 1978; 7: 601-610.

27. Farber K, Markworth S, Pannasch U, Nolte C, Prinz V, Kronenberg G et al. The ectonucleotidase cd39/ENTPDase1 modulates purinergic-mediated microglial migration. Glia 2008; 56: 331-341.

28. Kowaluk EA, Jarvis MF. Therapeutic potential of adenosine kinase inhibitors. Expert Opin Invest Drugs 2000; 9: 551-564.

29. Ren G, Li T, Lan JQ, Wilz A, Simon RP, Boison D. Lentiviral RNAi-induced downregulation of adenosine kinase in human mesenchymal stem cell grafts: a novel perspective for seizure control. Exp Neurol 2007; 208: 26-37.

30. Güttinger M, Padrun V, Pralong W, Boison D. Seizure suppression and lack of adenosine $A_{1}$ receptor desensitization after focal long-term delivery of adenosine by encapsulated myoblasts. Exp Neurol 2005; 193: 53-64.

31. Fedele DE, Koch P, Brüstle O, Scheurer L, Simpson EM, Mohler $\mathrm{H}$ et al. Engineering embryonic stem cell derived glia for adenosine delivery. Neurosci Lett 2004; 370: 160-165

32. Huber A, Padrun V, Deglon N, Aebischer P, Mohler H, Boison D. Grafts of adenosinereleasing cells suppress seizures in kindling epilepsy. Proc Natl Acad Sci USA 2001; 98: 7611-7616.

33. Fedele DE, Gouder N, Güttinger M, Gabernet L, Scheurer L, Rulicke T et al. Astrogliosis in epilepsy leads to overexpression of adenosine kinase resulting in seizure aggravation. Brain 2005; 128: 2383-2395.

34. Pak MA, Haas HL, Decking UKM, Schrader J. Inhibition of adenosine kinase increases endogenous adenosine and depresses neuronal activity in hippocampal slices. Neuropharmacol 1994; 33: 1049-1053.

35. Arch JR, Newsholme EA. Activities and some properties of $5^{\prime}$-nucleotidase, adenosine kinase and adenosine deaminase in tissues from vertebrates and invertebrates in relation to the control of the concentration and the physiological role of adenosine. Biochem J 1978; 174: 965-977.

36. Pignataro G, Maysami S, Studer FE, Wilz A, Simon RP, Boison D. Downregulation of hippocampal adenosine kinase after focal ischemia as potential endogenous neuroprotective mechanism. J Cereb Blood Flow Metab 2008; 28: 17-23.

37. Li T, Ren G, Lusardi T, Wilz A, Lan JQ, Iwasato T et al. Adenosine kinase is a target for the prediction and prevention of epileptogenesis in mice. J Clin Invest 2008; 118: 571-582.

38. Baldwin SA, Beal PR, Yao SY, King AE, Cass CE, Young JD. The equilibrative nucleoside transporter family, SLC29. Pflugers Arch 2004; 447: 735-743.

39. Boison D, Scheurer L, Zumsteg V, Rülicke T, Litynski P, Fowler B et al. Neonatal hepatic steatosis by disruption of the adenosine kinase gene. Proc Natl Acad Sci USA 2002; 99: 6985-6990

40. Peng L, Huang R, Yu AC, Fung KY, Rathbone MP, Hertz L. Nucleoside transporter expression and function in cultured mouse astrocytes. Glia 2005; 52: 25-35.

41. King AE, Ackley MA, Cass CE, Young JD, Baldwin SA. Nucleoside transporters: from scavengers to novel therapeutic targets. Trends Pharmacol Sci 2006; 27: 416-425

42. Carrier EJ, Auchampach JA, Hillard CJ. Inhibition of an equilibrative nucleoside transporter by cannabidiol: A mechanism of cannabinoid immunosuppression. Proc Natl Acad Sci USA 2006; 103: 7895-7900.

43. Fredholm BB, ljzerman AP, Jacobson KA, Klotz KN, Linden J. International Union of Pharmacology. XXV. Nomenclature and classification of adenosine receptors. Pharmacol Rev 2001; 53: 527-552.

44. Jin X, Shepherd RK, Duling BR, Linden J. Inosine binds to A3 adenosine receptors and stimulates mast cell degranulation. J Clin Invest 1997; 100: 2849-2857.

45. Fredholm BB, Irenius E, Kull B, Schulte G. Comparison of the potency of adenosine as an agonist at human adenosine receptors expressed in Chinese hamster ovary cells. Biochem Pharmacol 2001; 61: 443-448.

46. Schulte $G$, Fredholm $B B$. Human adenosine $A(1), A(2 A), A(2 B)$, and $A(3)$ receptors expressed in Chinese hamster ovary cells all mediate the phosphorylation of extracellularregulated kinase 1/2. Mol Pharmacol 2000; 58: 477-482.

47. Hammarberg $C$, Schulte G, Fredholm BB. Evidence for functional adenosine A3 receptors in microglia cells. J Neurochem 2003; 86: 1051-1054.

48. van Calker $\mathrm{D}$, Biber $\mathrm{K}$. The role of glial adenosine receptors in neural resilience and the neurobiology of mood disorders. Neurochem Res 2005; 30: 1205-1217.

49. Dare E, Schulte G, Karovic O, Hammarberg C, Fredholm BB. Modulation of glial cell functions by adenosine receptors. Physiol Behav 2007; 92: 15-20. 
50. Ciccarelli $R, D i$ lorio $P$, Ballerini $P$, Ambrosini G, Giuliani $P$, Tiboni $G M$ et al. Effects of exogenous ATP and related analogues on the proliferation rate of dissociated primary cultures of rat astrocytes. J Neurosci Res 1994; 39: 556-566.

51. Peakman MC, Hill SJ. Adenosine A1 receptor-mediated changes in basal and histaminestimulated levels of intracellular calcium in primary rat astrocytes. Br J Pharmacol 1995; 115: 801-810.

52. Biber K, Klotz KN, Berger M, Gebicke-Harter PJ, van Calker D. Adenosine A1 receptormediated activation of phospholipase $\mathrm{C}$ in cultured astrocytes depends on the level of receptor expression. J Neurosci 1997; 17: 4956-4964.

53. Cormier RJ, Mennerick S, Melbostad H, Zorumski CF. Basal levels of adenosine modulate mGluR5 on rat hippocampal astrocytes. Glia 2001; 33: 24-35.

54. Ciccarelli R, D'Alimonte I, Ballerini P, D’Auro M, Nargi E, Buccella S et al. 2007 Molecular signalling mediating the protective effect of $\mathrm{A} 1$ adenosine and mGlu3 metabotropic glutamate receptor activation against apoptosis by oxygen/glucose deprivation in cultured astrocytes. Mol Pharmacol 71: 1369-1380.

55. D'Alimonte I, Ballerini P, Nargi E, Buccella S, Giuliani P, Di lorio P et al. Staurosporineinduced apoptosis in astrocytes is prevented by $\mathrm{A} 1$ adenosine receptor activation. Neurosci Lett 2007; 418: 66-71.

56. Ishibashi T, Dakin KA, Stevens B, Lee PR, Kozlov SV, Stewart CL et al. Astrocytes promote myelination in response to electrical impulses. Neuron 2006; 49: 823-832.

57. Othman T, Yan H, Rivkees SA. Oligodendrocytes express functional A1 adenosine receptors that stimulate cellular migration. Glia 2003; 44: 166-172.

58. Kim M, Yu ZX, Fredholm BB, Rivkees SA. Susceptibility of the developing brain to acute hypoglycemia involving $\mathrm{A} 1$ adenosine receptor activation. Am J Physiol Endocrinol Metab 2005; 289: E562-E569.

59. Tsutsui S, Schnermann J, Noorbakhsh F, Henry S, Yong VW, Winston BW et al. A1 adenosine receptor upregulation and activation attenuates neuroinflammation and demyelination in a model of multiple sclerosis. J Neurosci 2004; 24: 1521-1529.

60. Synowitz M, Glass R, Farber K, Markovic D, Kronenberg G, Herrmann K et al. A1 adenosine receptors in microglia control glioblastoma-host interaction. Cancer Res 2006; 66: 8550-8557.

61. Halassa MM, Florian C, Fellin T, Munoz JR, Lee SY, Abel T et al. Astrocytic modulation of sleep homeostasis and cognitive consequences of sleep loss. Neuron 2009; 61 213-219.

62. Svenningsson P, Le Moine C, Fisone G, Fredholm BB. Distribution, biochemistry and function of striatal adenosine A2A receptors. Prog Neurobiol 1999; 59: 355-396.

63. Hettinger BD, Lee A, Linden J, Rosin DL. Ultrastructural localization of adenosine A2A receptors suggests multiple cellular sites for modulation of GABAergic neurons in rat striatum. J Comp Neurol 2001; 431: 331-346.

64. Hasko G, Pacher P, Vizi ES, Illes P. Adenosine receptor signaling in the brain immune system. Trends Pharmacol Sci 2005; 26: 511-516.

65. Saura J, Angulo E, Ejarque A, Casado V, Tusell JM, Moratalla R et al. Adenosine A2A receptor stimulation potentiates nitric oxide release by activated microglia. J Neurochem 2005; 95: 919-929.

66. Yu L-Q, Shen H-Y, Coelho J, Araújo I, Huang Q-Y, Day Y-J et al. A2A receptor antagonists exert motor and protective effects by distinct cellular mechanism in MPTP model of PD. Ann Neurol 2008; 63: 338-346.

67. Pickel VM, Chan J, Linden J, Rosin DL. Subcellular distributions of adenosine A1 and A2A receptors in the rat dorsomedial nucleus of the solitary tract at the level of the area postrema. Synapse 2006; 60: 496-509.

68. Cunha RA. Neuroprotection by adenosine in the brain: From $A 1$ receptor activation to A2A receptor blockade. Purinergic Signal 2005; 1: 111-134.

69. Li XX, Nomura T, Aihara H, Nishizaki T. Adenosine enhances glial glutamate efflux via A2a adenosine receptors. Life Sci 2001; 68: 1343-1350.

70. Nishizaki T, Nagai K, Nomura T, Tada H, Kanno T, Tozaki H et al. A new neuromodulatory pathway with a glial contribution mediated via A(2a) adenosine receptors. Glia 2002; 39 133-147.

71. Hindley S, Herman MA, Rathbone MP. Stimulation of reactive astrogliosis in vivo by extracellular adenosine diphosphate or an adenosine A2 receptor agonist. J Neurosci Res 1994; 38: 399-406.

72. Brambilla R, Cottini L, Fumagalli M, Ceruti S, Abbracchio MP. Blockade of A2A adenosine receptors prevents basic fibroblast growth factor-induced reactive astrogliosis in rat striatal primary astrocytes. Glia 2003; 43: 190-194.

73. Brodie $\mathrm{C}$, Blumberg PM, Jacobson KA. Activation of the A2A adenosine receptor inhibits nitric oxide production in glial cells. FEBS Lett 1998; 429: 139-142.

74. Fiebich BL, Biber K, Lieb K, van Calker D, Berger M, Bauer J et al. Cyclooxygenase-2 expression in rat microglia is induced by adenosine A2a-receptors. Glia 1996; 18 152-160.

75. Heese K, Fiebich BL, Bauer J, Otten U. Nerve growth factor (NGF) expression in rat microglia is induced by adenosine A2a-receptors. Neurosci Lett 1997; 231: 83-86.

76. Peakman MC, Hill SJ. Adenosine A2B-receptor-mediated cyclic AMP accumulation in primary rat astrocytes. Br J Pharmacol 1994; 111: 191-198.

77. Pilitsis JG, Kimelberg HK. Adenosine receptor mediated stimulation of intracellular calcium in acutely isolated astrocytes. Brain Res 1998; 798: 294-303.

78. Schwaninger M, Neher M, Viegas E, Schneider A, Spranger M. Stimulation of interleukin6 secretion and gene transcription in primary astrocytes by adenosine. $J$ Neurochem 1997; 69: 1145-1150
79. Lazarowski ER, Boucher RC. Purinergic receptors in airway epithelia. Curr Opin Pharmacol 2009; 9: 262-267.

80. Corset V, Nguyen-Ba-Charvet KT, Forcet C, Moyse E, Chedotal A, Mehlen P. Netrin-1mediated axon outgrowth and cAMP production requires interaction with adenosine $\mathrm{A} 2 \mathrm{~b}$ receptor. Nature 2000; 407: 747-750.

81. Stein E, Zou Y, Poo M, Tessier-Lavigne M. Binding of DCC by netrin-1 to mediate axon guidance independent of adenosine A2B receptor activation. Science 2001; 291: 1976-1982.

82. McKenna WL, Wong-Staal C, Kim GC, Macias H, Hinck L, Bartoe JL. Netrin-1independent adenosine $\mathrm{A} 2 \mathrm{~b}$ receptor activation regulates the response of axons to netrin-1 by controlling cell surface levels of UNC5A receptors. J Neurochem 2008; 104: 1081-1090.

83. Wittendorp MC, Boddeke HW, Biber K. Adenosine A3 receptor-induced CCL2 synthesis in cultured mouse astrocytes. Glia 2004; 46: 410-418.

84. Hammarberg C, Fredholm BB, Schulte G. Adenosine A3 receptor-mediated regulation of p38 and extracellular-regulated kinase ERK1/2 via phosphatidylinositol-3'-kinase. Biochem Pharmacol 2004; 67: 129-134

85. Davalos D, Grutzendler J, Yang G, Kim JV, Zuo Y, Jung S et al. ATP mediates rapid microglial response to local brain injury in vivo. Nat Neurosci 2005; 8: 752-758.

86. Haynes SE, Hollopeter G, Yang G, Kurpius D, Dailey ME, Gan WB et al. The P2Y12 receptor regulates microglial activation by extracellular nucleotides. Nat Neurosci 2006; 9 1512-1519.

87. Chen $Y$, Corriden R, Inoue $Y$, Yip L, Hashiguchi N, Zinkernagel A et al. ATP release guides neutrophil chemotaxis via P2Y2 and A3 receptors. Science 2006; 314: 1792-1795.

88. Miller RJ, Rostene W, Apartis E, Banisadr G, Biber K, Milligan ED et al. Chemokine action in the nervous system. J Neurosci 2008; 28: 11792-11795.

89. Iadecola C, Nedergaard M. Glial regulation of the cerebral microvasculature. Nat Neurosci 2007; 10: 1369-1376.

90. Koehler RC, Roman RJ, Harder DR. Astrocytes and the regulation of cerebral blood flow. Trends Neurosci 2009; 32: 160-169.

91. Wilhelmsson U, Bushong EA, Price DL, Smarr BL, Phung V, Terada M et al. Redefining the concept of reactive astrocytes as cells that remain within their unique domains upon reaction to injury. Proc Natl Acad Sci USA 2006; 103: 17513-17518.

92. Oberheim NA, Tian GF, Han X, Peng W, Takano T, Ransom B et al. Loss of astrocytic domain organization in the epileptic brain. J Neurosci 2008; 28: 3264-3276.

93. Oberheim NA, Wang X, Goldman S, Nedergaard M. Astrocytic complexity distinguishes the human brain. Trends Neurosci 2006; 29: 547-553.

94. Dirnagl U, Niwa K, Lindauer U, Villringer A. Coupling of cerebral blood flow to neurona activation: role of adenosine and nitric oxide. Am J Physiol 1994; 267: H296-H301.

95. Iliff JJ, D'Ambrosio R, Ngai AC, Winn HR. Adenosine receptors mediate glutamateevoked arteriolar dilation in the rat cerebral cortex. Am J Physiol Heart Circ Physiol 2003 284: $\mathrm{H} 1631-\mathrm{H} 1637$.

96. Ohata $\mathrm{H}$, Cao $\mathrm{S}$, Koehler $\mathrm{RC}$. Contribution of adenosine $\mathrm{A} 2 \mathrm{~A}$ and $\mathrm{A} 2 \mathrm{~B}$ receptors and heme oxygenase to AMPA-induced dilation of pial arterioles in rats. Am J Physiol Regul Integr Comp Physiol 2006; 291: R728-R735.

97. Fields RD, Burnstock G. Purinergic signalling in neuron-glia interactions. Nat Rev Neurosci 2006; 7: 423-436.

98. Jimenez Al, Castro E, Mirabet M, Franco R, Delicado EG, Miras-Portugal MT. Potentiation of ATP calcium responses by A2B receptor stimulation and other signals coupled to Gs proteins in type-1 cerebellar astrocytes. Glia 1999; 26: 119-128.

99. Alloisio S, Cugnoli C, Ferroni S, Nobile M. Differential modulation of ATP-induced calcium signalling by $A 1$ and $A 2$ adenosine receptors in cultured cortical astrocytes. $B r J$ Pharmacol 2004; 141: 935-942.

100. Xu HL, Pelligrino DA. ATP release and hydrolysis contribute to rat pial arteriolar dilatation elicited by neuronal activation. Exp Physiol 2007; 92: 647-651.

101. Xu HL, Mao L, Ye S, Paisansathan C, Vetri F, Pelligrino DA. Astrocytes are a key conduit for upstream signaling of vasodilation during cerebral cortical neuronal activation in vivo. Am J Physiol Heart Circ Physiol 2008; 294: H622-H632.

102. Takano T, Oberheim N, Cotrina ML, Nedergaard M. Astrocytes and ischemic injury. Stroke 2009; 40: S8-12.

103. Eid T, Williamson A, Lee TS, Petroff OA, de Lanerolle NC. Glutamate and astrocytes key players in human mesial temporal lobe epilepsy? Epilepsia 2008; 49 (Suppl 2): 42-52.

104. Tanaka K, Watase K, Manabe T, Yamada K, Watanabe M, Takahashi K et al. Epilepsy and exacerbation of brain injury in mice lacking the glutamate transporter GLT-1. Science 1997; 276: 1699-1702.

105. Rothstein JD, Dykes-Hoberg M, Pardo CA, Bristol LA, Jin L, Kuncl RW et al. Knockout of glutamate transporters reveals a major role for astroglial transport in excitotoxicity and clearance of glutamate. Neuron 1996; 16: 675-686.

106. Eid T, Thomas MJ, Spencer DD, Runden-Pran E, Lai JC, Malthankar GV et al. Loss of glutamine synthetase in the human epileptogenic hippocampus: possible mechanism for raised extracellular glutamate in mesial temporal lobe epilepsy. Lancet 2004; 363: $28-37$.

107. Volterra A, Meldolesi J. Astrocytes, from brain glue to communication elements: the revolution continues. Nat Rev Neurosci 2005: 6: 626-640.

108. Bezzi P, Gundersen V, Galbete JL, Seifert G, Steinhauser C, Pilati E et al. Astrocytes contain a vesicular compartment that is competent for regulated exocytosis of glutamate. Nat Neurosci 2004; 7: 613-620. 
109. Lee SY, Haydon PG. Astrocytic glutamate targets NMDA receptors. J Physiol 2007; 581 887-888.

110. Nedergaard M. Direct signaling from astrocytes to neurons in cultures of mammalian brain cells. Science 1994; 263: 1768-1771.

111. Parpura V, Basarsky TA, Liu F, Jeftinija K, Jeftinija S, Haydon PG. Glutamate-mediated astrocyte-neuron signalling. Nature 1994; 369: 744-747.

112. Stevens B, Porta S, Haak LL, Gallo V, Fields RD. Adenosine: a neuron-glial transmitter promoting myelination in the CNS in response to action potentials. Neuron 2002; 36 855-868.

113. Jourdain $P$, Bergersen LH, Bhaukaurally $K$, Bezzi $P$, Santello $M$, Domercq $M$ et al. Glutamate exocytosis from astrocytes controls synaptic strength. Nat Neurosci 2007; 10 331-339.

114. Yang Y, Ge W, Chen Y, Zhang Z, Shen W, Wu C et al. Contribution of astrocytes to hippocampal long-term potentiation through release of D-serine. Proc Natl Acad Sci USA 2003; 100: 15194-15199.

115. Nagai M, Re DB, Nagata T, Chalazonitis A, Jessell TM, Wichterle $\mathrm{H}$ et al. Astrocytes expressing ALS-linked mutated SOD1 release factors selectively toxic to motor neurons. Nat Neurosci 2007; 10: 615-622.

116. Boillee S, Vande Velde C, Cleveland DW. ALS: a disease of motor neurons and their nonneuronal neighbors. Neuron 2006; 52: 39-59.

117. Yu L, Shen HY, Coelho JE, Araujo IM, Huang QY, Day YJ et al. 2008 Adenosine A2A receptor antagonists exert motor and neuroprotective effects by distinct cellular mechanisms. Ann Neurol 63: 338-346.

118. Lovatt D, Sonnewald U, Waagepetersen HS, Schousboe A, He W, Lin JH et al. The transcriptome and metabolic gene signature of protoplasmic astrocytes in the adult murine cortex. J Neurosci 2007; 27: 12255-12266.

119. Tian GF, Azmi H, Takano T, Xu QW, Peng WG, Lin J et al. An astrocytic basis of epilepsy. Nat Med 2005: 11: 973-981.

120. Binder DK, Steinhauser C. Functional changes in astroglial cells in epilepsy. Glia 2006 54: 358-368.

121. Li T, Lan JQ, Fredholm BB, Simon RP, Boison D. Adenosine dysfunction in astrogliosis: cause for seizure generation? Neuron Glia Biol 2007; 3: 353-366

122. Etherington LA, Patterson GE, Meechan L, Boison D, Irving AJ, Dale $\mathrm{N}$ et al. Astrocytic adenosine kinase regulates basal synaptic adenosine levels and seizure activity but not activity-dependent adenosine release in the hippocampus. Neuropharmacology 2009; 56 429-437.

123. Boison D. Adenosine augmentation therapies (AATs) for epilepsy: prospect of cell and gene therapies. Epilepsy Res 2009; 85: 131-141.

124. Boison D. Engineered adenosine-releasing cells for epilepsy therapy: human mesenchymal stem cells and human embryonic stem cells. Neurotherapeutics 2009; 6 : 278-283.

125. Bell MJ, Kochanek PM, Carcillo JA, Mi Z, Schiding JK, Wisniewski SR et al. Interstitial adenosine, inosine, and hypoxanthine are increased after experimental traumatic brain injury in the rat. J Neurotrauma 1998; 15: 163-170.

126. Kochanek PM, Vagni VA, Janesko KL, Washington CB, Crumrine PK, Garman RH et al. Adenosine $\mathrm{A} 1$ receptor knockout mice develop lethal status epilepticus after experimental traumatic brain injury. J Cereb Blood Flow Metab 2006; 26: 565-575.

127. Fedele DE, Li T, Lan JQ, Fredholm BB, Boison D. Adenosine $A_{1}$ receptors are crucial in keeping an epileptic focus localized. Exp Neurol 2006; 200: 184-190.

128. Li W, Dai S, An J, Xiong R, Li P, Chen X et al. Genetic inactivation of adenosine A2A receptors attenuates acute traumatic brain injury in the mouse cortical impact model. Exp Neurol 2009; 215: 69-76.

129. Sachse KT, Jackson EK, Wisniewski SR, Gillespie DG, Puccio AM, Clark RS et al. Increases in cerebrospinal fluid caffeine concentration are associated with favorable outcome after severe traumatic brain injury in humans. J Cereb Blood Flow Metab 2007; 28: $395-401$

130. Li W, Dai S, An J, Li P, Chen X, Xiong R et al. Chronic but not acute treatment with caffeine attenuates traumatic brain injury in the mouse cortical impact model. Neuroscience 2008; 151: 1198-1207.

131. Gouder N, Scheurer L, Fritschy J-M, Boison D. Overexpression of adenosine kinase in epileptic hippocampus contributes to epileptogenesis. J Neurosci 2004; 24: 692-701.

132. Ferre S, von Euler G, Johansson B, Fredholm BB, Fuxe K. Stimulation of high-affinity adenosine $\mathrm{A} 2$ receptors decreases the affinity of dopamine $\mathrm{D} 2$ receptors in rat striatal membranes. Proc Natl Acad Sci USA 1991; 88: 7238-7241.

133. Richardson PJ, Gubitz AK, Freeman TC, Dixon AK. Adenosine receptor antagonists and Parkinson's disease: actions of the A2A receptor in the striatum. Adv Neurol 1999; 80 111-119

134. Schwarzschild MA, Agnati L, Fuxe K, Chen JF, Morelli M. Targeting adenosine A2A receptors in Parkinson's disease. Trends Neurosci 2006; 29: 647-654

135. Jenner P, Mori A, Hauser R, Morelli M, Fredholm BB, Chen JF. Adenosine, adenosine $\mathrm{A}(2 \mathrm{~A})$ antagonists, and Parkinson's disease. Parkinsonism Relat Disord 2009; 15 406-413.

136. Schwarzschild MA. Adenosine A2A antagonists as neurotherapeutics: crossing the bridge. Prog Neurobiol 2007; 83: 261-262.

137. Ross GW, Abbott RD, Petrovitch H, Morens DM, Grandinetti A, Tung KH et al. Association of coffee and caffeine intake with the risk of Parkinson disease. JAMA 2000; 283 2674-2679.
138. Ascherio A, Zhang SM, Hernan MA, Kawachi I, Colditz GA, Speizer FE et al. Prospective study of caffeine consumption and risk of Parkinson's disease in men and women. Ann Neurol 2001; 50: 56-63.

139. Saaksjarvi K, Knekt $P$, Rissanen $H$, Laaksonen MA, Reunanen A, Mannisto S Prospective study of coffee consumption and risk of Parkinson's disease. Eur J Clin Nutr 2008; 62: 908-915.

140. Chen JF, Xu K, Petzer JP, Staal R, Xu YH, Beilstein M et al. Neuroprotection by caffeine and $\mathrm{A}(2 \mathrm{~A})$ adenosine receptor inactivation in a model of Parkinson's disease. J Neurosci 2001; 21: RC143.

141. Ikeda K, Kurokawa M, Aoyama S, Kuwana Y. Neuroprotection by adenosine A2A receptor blockade in experimental models of Parkinson's disease. J Neurochem 2002; 80: 262-270.

142. Kelly S, Zhang ZJ, Zhao H, Xu L, Giffard RG, Sapolsky RM et al. Gene transfer of HSP72 protects cornu ammonis 1 region of the hippocampus neurons from global ischemia: influence of Bcl-2. Ann Neurol 2002; 52: 160-167.

143. Chen JF, Sonsalla PK, Pedata F, Melani A, Domenici MR, Popoli P et al. Adenosine A2A receptors and brain injury: broad spectrum of neuroprotection, multifaceted actions and 'fine tuning' modulation. Prog Neurobiol 2007; 83: 310-331.

144. Pierri M, Vaudano E, Sager T, Englund U. KW-6002 protects from MPTP induced dopaminergic toxicity in the mouse. Neuropharmacology 2005; 48: 517-524

145. Hagberg H, Andersson P, Lacarewicz J, Jacobson I, Butcher S, Sandberg M 1987 Extracellular adenosine, inosine, hypoxanthine, and xanthine in relation to tissue nucleotides and purines in rat striatum during transient ischemia. $J$ Neurochem 49: 227-231.

146. Kopf SR, Melani A, Pedata F, Pepeu G. Adenosine and memory storage: effect of $A(1)$ and A(2) receptor antagonists. Psychopharmacology (Berl) 1999; 146: 214-219.

147. Gianfriddo M, Corsi C, Melani A, Pezzola A, Reggio R, Popoli P et al. Adenosine A(2A) antagonism increases striatal glutamate outflow in the quinolinic acid rat model of Huntington's disease. Brain Res 2003; 979: 225-229.

148. Latini S, Pedata F. Adenosine in the central nervous system: release mechanisms and extracellular concentrations. J Neurochem 2001; 79: 463-484.

149. Latini S, Bordoni F, Corradetti R, Pepeu G, Pedata F. Temporal correlation between adenosine outflow and synaptic potential inhibition in rat hippocampal slices during ischemia-like conditions. Brain Res 1998; 794: 325-328.

150. Matsumoto K, Graf R, Rosner G, Shimada N, Heiss WD. Flow thresholds for extracellular purine catabolite elevation in cat focal ischemia. Brain Res 1992; 579: 309-314.

151. Dux E, Fastbom J, Ungerstedt U, Rudolphi K, Fredholm BB. Protective effect of adenosine and a novel xanthine derivative propentofylline on the cell damage after bilateral carotid occlusion in the gerbil hippocampus. Brain Res 1990; 516: 248-256.

152. Frenguelli BG, Wigmore G, Llaudet $E$, Dale N. Temporal and mechanistic dissociation of ATP and adenosine release during ischaemia in the mammalian hippocampus. $J$ Neurochem 2007; 101: 1400-1413.

153. Phillis JW, Perkins LM, Smith-Barbour M, O'Regan MH. Transmitter amino acid release from rat neocortex: complete versus incomplete ischemia models. Neurochem Res 1994; 19: 1387-1392.

154. Phillis JW, Smith-Barbour M, O'Regan MH. Changes in extracellular amino acid neurotransmitters and purines during and following ischemias of different durations in the rat cerebral cortex. Neurochem Int 1996; 29: 115-120.

155. Schwarzschild MA, Chen JF, Ascherio A. Caffeinated clues and the promise of adenosine A(2A) antagonists in PD. Neurology 2002; 58: 1154-1160.

156. Ribeiro JA, Sebastiao AM, de Mendonca A 2002 Adenosine receptors in the nervous system: pathophysiological implications. Prog Neurobiol 68: 377-392.

157. Ongini E, Adami M, Ferri C, Bertorelli R. Adenosine A2A receptors and neuroprotection. Ann NY Acad Sci 1997; 825: 30-48.

158. Fredholm BB, Cunha RA, Svenningsson P. Pharmacology of adenosine A(2A) receptors and therapeutic applications. Curr Top Med Chem 2003; 3: 413-426.

159. Cunha RA. Adenosine as a neuromodulator and as a homeostatic regulator in the nervous system: different roles, different sources and different receptors. Neurochem Int 2001; 38: 107-125.

160. Rudolphi KA, Schubert P, Parkinson FE, Fredholm BB. Neuroprotective role of adenosine in cerebral ischemia. Trends Pharmacol Sci 1992; 13: 439-445.

161. Fredholm BB. Adenosine and neuroprotection In: Green AR, Cross AJ (eds). Neuroprotective agents and cerebral ischemia. Academic Press: London, $1996 \mathrm{pp}$ 259-280.

162. Kitagawa H, Mori A, Shimada J, Mitsumoto Y, Kikuchi T. Intracerebral adenosine infusion improves neurological outcome after transient focal ischemia in rats. Neurol Res 2002; 24: 317-323.

163. Phillis JW, O'Regan MH. Deoxycoformycin antagonizes ischemia-induced neuronal degeneration. Brain Res Bull 1989; 22: 537-540.

164. Phillis JW, Walter GA, Simpson RE. Brain adenosine and transmitter amino acid release from the ischemic rat cerebral cortex: effects of the adenosine deaminase inhibitor deoxycoformycin. J Neurochem 1991; 56: 644-650.

165. Lin Y, Phillis JW. Deoxycoformycin and oxypurinol: protection against focal ischemic brain injury in the rat. Brain Res 1992; 571: 272-280.

166. Gidday JM. Cerebral preconditioning and ischaemic tolerance. Nat Rev Neurosci 2006; 7 437-448. 
167. Miller LP, Jelovich LA, Yao L, DaRe J, Ugarkar B, Foster AC. Pre- and peristroke treatment with the adenosine kinase inhibitor, $5^{\prime}$-deoxyiodotubercidin, significantly reduces infarct volume after temporary occlusion of the middle cerebral artery in rats. Neurosci Lett 1996; 220: 73-76.

168. DeLeo J, Schubert $P$, Kreutzberg GW. Protection against ischemic brain damage using propentofylline in gerbils. Stroke 1988; 19: 1535-1539.

169. Andine P, Rudolphi KA, Fredholm BB, Hagberg H. Effect of propentofylline (HWA 285) on extracellular purines and excitatory amino acids in $\mathrm{CA} 1$ of rat hippocampus during transient ischaemia. Br J Pharmacol 1990; 100: 814-818.

170. Kano T, Katayama Y, Kawamata T, Hirota H, Tsubokawa T. Propentofylline administered by microdialysis attenuates ischemia-induced hippocampal damage but not excitatory amino acid release in gerbils. Brain Res 1994; 641: 149-154.

171. Matsumoto K, Sakaki T, Kohmura E, Hayakawa T, Yamada K. Amelioration of ischemic brain damage by the preischemic administration of propentofylline (HWA285) in a rat foca ischemia. Brain Res 1996; 723: 228-230.

172. Fritschy J-M, Johnson DJ, Mohler H, Rudolph U. Independent assembly and subcellular targeting of $\mathrm{GABA}_{\mathrm{A}}$-receptor subtypes demonstrated in mouse hippocampal and olfactory neurons in vivo. Neurosci Lett 1998; 249: 99-102.

173. Parkinson FE, Xiong W, Zamzow CR. Astrocytes and neurons: different roles in regulating adenosine levels. Neurol Res 2005; 27: 153-160.

174. Pignataro G, Simon RP, Boison D. Transgenic overexpression of adenosine kinase aggravates cell death in ischemia. J Cereb Blood Flow Metab 2007; 27 $1-5$.

175. Zetterstrom T, Fillenz M. Adenosine agonists can both inhibit and enhance in vivo striata dopamine release. Eur J Pharmacol 1990; 180: 137-143.

176. Corradetti R, Lo Conte G, Moroni F, Passani MB, Pepeu G. Adenosine decreases aspartate and glutamate release from rat hippocampal slices. Eur J Pharmacol 1984; 104 $19-26$.

177. Greene RW, Haas HL. The electrophysiology of adenosine in the mammalian central nervous system. Prog Neurobiol 1991; 36: 329-341.

178. Olsson T, Cronberg T, Rytter A, Asztely F, Fredholm BB, Smith ML et al. Deletion of the adenosine $A 1$ receptor gene does not alter neuronal damage following ischaemia in vivo or in vitro. Eur J Neurosci 2004; 20: 1197-1204.

179. Phillis JW. The effects of selective $A 1$ and $A 2 a$ adenosine receptor antagonists on cerebral ischemic injury in the gerbil. Brain Res 1995; 705: 79-84

180. Von Lubitz DK, Lin RC, Jacobson KA. Cerebral ischemia in gerbils: effects of acute and chronic treatment with adenosine A2A receptor agonist and antagonist. Eur J Pharmacol 1995; 287: 295-302.

181. Bona E, Aden U, Gilland E, Fredholm BB, Hagberg H. Neonatal cerebral hypoxiaischemia: the effect of adenosine receptor antagonists. Neuropharmacology 1997; 36 $1327-1338$.
182. Monopoli A, Lozza G, Forlani A, Mattavelli A, Ongini E. Blockade of adenosine A2A receptors by $\mathrm{SCH} 58261$ results in neuroprotective effects in cerebral ischaemia in rats. Neuroreport 1998; 9: 3955-3959.

183. Pedata F, Gianfriddo M, Turchi D, Melani A. The protective effect of adenosine A2A receptor antagonism in cerebral ischemia. Neurol Res 2005; 27: 169-174.

184. Melani A, Gianfriddo M, Vannucchi MG Cipriani S, Baraldi PG, Giovannini MG et al. The selective $\mathrm{A}(2 \mathrm{~A})$ receptor antagonist $\mathrm{SCH} 58261$ protects from neurological deficit, brain damage and activation of p38 MAPK in rat focal cerebral ischemia. Brain Res 2006 1073-1074: 470-480.

185. Chen JF, Huang Z, Ma J, Zhu J, Moratalla R, Standaert D et al. A(2A) adenosine receptor deficiency attenuates brain injury induced by transient focal ischemia in mice. $J$ Neurosci 1999; 19: 9192-9200.

186. Pedata F, Corsi C, Melani A, Bordoni F, Latini S. Adenosine extracellular brain concentrations and role of A2A receptors in ischemia. Ann NY Acad Sci 2001; 939: 74-84.

187. Marcoli M, Raiteri L, Bonfanti A, Monopoli A, Ongini E, Raiteri M et al. Sensitivity to selective adenosine $A 1$ and $A 2 A$ receptor antagonists of the release of glutamate induced by ischemia in rat cerebrocortical slices. Neuropharmacology 2003; 45: 201-210.

188. Aden U, Halldner L, Lagercrantz H, Dalmau I, Ledent C, Fredholm BB. Aggravated brain damage after hypoxic ischemia in immature adenosine A2A knockout mice. Stroke 2003; 34: 739-744.

189. Phillis JW. Adenosine and adenine nucleotides as regulators of cerebral blood flow: roles of acidosis, cell swelling, and KATP channels. Crit Rev Neurobiol 2004; 16: 237-270.

190. von Lubitz DKJE. Adenosine and cerebral ischemia: therapeutic future or death of a brave concept? Eur J Pharmacol 1999; 365: 9-25.

191. Chen JF, Pedata F. Modulation of ischemic brain injury and neuroinflammation by adenosine $\mathrm{A}(2 \mathrm{~A})$ receptors. Curr Pharmaceutical Design 2008; 14: 1490-1499.

192. Irving EA, Barone FC, Reith AD, Hadingham SJ, Parsons AA. Differential activation of MAPK/ERK and p38/SAPK in neurones and glia following focal cerebral ischaemia in the rat. Brain Res Mol Brain Res 2000; 77: 65-75.

193. Wu DC, Ye W, Che XM, Yang GY. Activation of mitogen-activated protein kinases after permanent cerebral artery occlusion in mouse brain. J Cereb Blood Flow Metab 2000; 20 $1320-1330$.

194. Barone FC, Irving EA, Ray AM, Lee JC, Kassis S, Kumar S et al. Inhibition of p38 mitogen-activated protein kinase provides neuroprotection in cerebral focal ischemia. Med Res Rev 2001; 21: 129-145

195. Gao Y, Signore AP, Yin W, Cao G, Yin XM, Sun F et al. Neuroprotection against foca ischemic brain injury by inhibition of c-Jun $\mathrm{N}$-terminal kinase and attenuation of the mitochondrial apoptosis-signaling pathway. J Cereb Blood Flow Metab 2005; 25: 694-712.

196. Kawasaki H, Morooka T, Shimohama S, Kimura J, Hirano T, Gotoh Y et al. Activation and involvement of p38 mitogen-activated protein kinase in glutamate-induced apoptosis in rat cerebellar granule cells. J Biol Chem 1997; 272: 18518-18521. 